\title{
Accuracy of Doppler Ultrasonography in Assessment of Lower Extremity Peripheral Arterial Diseases
}

\author{
Samia Perwaiz Khan, SafiaIzhar \\ Jinnah Medical \& Dental College (Medicare Cardiac \& General Hospital) Karachi, Pakistan \\ Email:samiaphk@gmail.com, safiaizhar123@gmail.com
}

How to cite this paper: Khan, S.P. and SafiaIzhar (2018) Accuracy of Doppler Ultrasonography in Assessment of Lower Extremity Peripheral Arterial Diseases. International Journal of Clinical Medicine, 9, 505-512.

https://doi.org/10.4236/ijcm.2018.96043

Received: April 24, 2018

Accepted: June 10, 2018

Published: June 13, 2018

Copyright (c) 2018 by authors and Scientific Research Publishing Inc. This work is licensed under the Creative Commons Attribution International License (CC BY 4.0).

http://creativecommons.org/licenses/by/4.0/

c) (i) Open Access

\begin{abstract}
Doppler ultrasound scan is a non-invasive, cheap and convenient tool and it complements angiography, Computed tomography angiography (CTA), magnetic resonance angiography (MRA) and catheter digital subtraction angiography (DSA) in screening, diagnosis, treatment and follow-up of peripheral vascular diseases. Symptoms of peripheral vascular diseases are becoming more common due to rise in incidence of diseases and risk factors (diabetes mellitus, dyslipidemias, smoking, sedentary lifestyle). Due to limited availability of highly specific tools such as CT angiography, magnetic resonance angiography (MRA) and DSA (digital subtraction angiography) in many developing countries, doppler ultrasound is gaining more importance. Early determination of peripheral arterial diseases is beneficial in prevention of complications as severity increases may cause intermittent claudication, pain, tissue loss, including ulceration and gangrene (as the diseases progresses) and early management of arteriosclerosis will be beneficial to prevent these complications.
\end{abstract}

\section{Keywords}

PAD Peripheral Arterial Diseases, Doppler Ultrasonography, T2DM Type 2Diabetes Mellitus

\section{Introduction}

Doppler ultrasound scan is a highly useful non-invasive and reasonable tool for determination of CIMT, peripheral arterial diseases, renal artery stenosis due to atherosclerosis caused by diabetes mellitus, hyperlipidemia and smoking [1] [2] [3] [4]. Computed tomography angiography (CTA) and magnetic resonance an- 
giography (MRA) are highly accurate cross-sectional vascular imaging modalities that have almost completely replaced diagnostic catheter angiography for the evaluation of the mesenteric vasculature. Intra-arterial digital subtraction angiography (DSA), contrast enhanced magnetic resonance angiography (MRA) and computerized tomographic angiography (CTA) have been as imaging modalities in lower extremity ischemia. DSA is an invasive technique most often performed from a femoral arterial puncture and requires injection of arterial contrast, which can cause allergic reaction, in patients with renal insufficiency can worsen renal failure. DSA gives the highest degree of spatial resolution and image quality. It is also the only modality where diagnosis and treatment of arterial diseases can be performed together. MRA is noninvasive and when done with gadolinium, contrast injection provides arterial images similar to DSA. There is increased risk of nephrogenic systemic fibrosis, gadolinium-enhanced MRA cannot be used in patients with renal insufficiency. CTA is also noninvasive and rapid, with better spatial resolution than MRA. It requires large volume of contrast infusion and exposes patients to high-dose radiations, in patients with heavily calcified arteries (diabetic patients) can cause errors in interpretation, which limits its use in these patients. For patients with planned surgical bypass DSA and MRA provide high quality resolution of arteries of lower extremities. In renal dysfunction DSA and CTA can be performed. Such patients need intravenous normal saline or bicarbonate infusion before the procedure to reduce the risk of contrast-induced nephropathy.

CTA is the technique of choice when evaluating patients with suspected mesenteric ischemia; it permits to differentiate between occlusive and non-occlusive etiologies [5] [6]. Advances in both CTA (computed tomography angiography) and MRA (magnetic resonance angiography) provide clinicians the high resolution, 3-dimensional (3-D) road map of the peripheral arterial tree in patients particularly when planning revascularization strategies. Invasive, digital subtraction angiography (DSA) has been useful for evaluation of lower extremity atherosclerosis. Although DSA is one of the techniques for diagnosing significant arterial stenosis or obstruction, it provides a $2 \mathrm{D}$ view of the vessels, which may underestimate the degree of stenosis in tortuous vessels [4]. Furthermore, there are associated serious risks with arterial access by ionizing radiation and the use of iodinated contrast media [7] [8] [9].

Prospective study done for comparison between contrast-enhanced MR angiography and duplex US provides evidence that contrast-enhanced MR angiography is more sensitive and specific for diagnosis and pre-interventional work-up of PAD [8] [9] [10] [11]. Doppler studies were performed by a single radiologist using color Doppler ultrasonography (Logic 7; General Electronics, Milwaukee, WI, USA). Information on the presence and grade of stenosis, post-stenotic turbulence, peak systolic velocity, end diastolic velocity, and the presence of collaterals and their flow characteristics were assessed on color Doppler imaging [12] [13] [14]. The degree of stenosis was graded according to 
Jager's criteria [15] [16]: normal, triphasic waveform with thin spectral band. Grade I, $1 \%$ to $19 \%$ stenosis: normal triphasic flow with normal peak systolic velocity with spectral broadening. Grade II, $20 \%$ to $49 \%$ stenosis: triphasic waveform with an increase in peak systolic velocity $\geq 30 \%$ with respect to the proximal recording site. Marked spectral broadening. Grade III, 50\% to $99 \%$ stenosis: monophasic waveform with an increase in peak systolic velocity $\geq$ $100 \%$ and marked spectral broadening. Distal waveform is abnormal. Grade IV, $100 \%$ stenosis: no forward flow detected with altered flow patterns both proximal and distal to the stenosis [17] [18].

Peripheral arterial diseases (PAD) of lower limb are spectrum of atherosclerotic diseases range from mild plaque formation to chronic total vessel occlusion. Patient may remain asymptomatic but as severity increases develops intermittent claudication, pain tissue loss include ulceration and gangrene as the diseases progresses [19].

Therefore the early study by Doppler ultrasound describes the spectrum of abnormalities of the peripheral arteries at Medicare cardiac and general hospitals. Along with the signs and symptoms of vascular occlusion which corresponds with the findings on Doppler ultrasound [20], Table 1 showing comparison of CTA, MRA and duplex ultrasonography.

The aim/Objective of this study was to find the accuracy and compatibility of ultrasonography in diagnosis of lower extremity arterial diseases.

\section{Material \& Methods}

All 36 patients were included from Medicare Cardiac \& General Hospital from 2017-2018. All examinations were performed by using Doppler ultrasonography

Table 1. Comparison between CTA, MRA and duplex ultrasonography for diagnosis of PAD.

\begin{tabular}{|c|c|c|}
\hline Imaging Modality & Strengths & Limitations \\
\hline Duplex ultrasonography (U/S) & $\begin{array}{l}\text { 1) Easily accessible } \\
\text { 2) Low cost } \\
\text { 3) No exposure to radiations } \\
\text { 4) No administration of } \\
\text { contrast }\end{array}$ & $\begin{array}{l}\text { 1) Less accurate in aorticoiliac } \\
\text { region in obese patients or gas } \\
\text { in intestine } \\
\text { 2) Limited sensitivity to } \\
\text { stenosis at multiple-levels } \\
\text { 3) Limited sensitivity in heavily } \\
\text { calcified vessels }\end{array}$ \\
\hline $\begin{array}{l}\text { Magnetic resonance } \\
\text { angiography (MRA) }\end{array}$ & $\begin{array}{l}\text { 1) Gadolinium enhanced and } \\
\text { non-contrast approaches } \\
\text { available } \\
\text { 2) Contrast used is neither } \\
\text { iodinated nor ionized }\end{array}$ & $\begin{array}{l}\text { 1) In-stent restenosis limit by } \\
\text { metal artifact } \\
\text { 2) In patients with advanced } \\
\text { renal diseases risk of NSF }\end{array}$ \\
\hline $\begin{array}{l}\text { Computed tomography } \\
\text { angiography (CTA) }\end{array}$ & $\begin{array}{l}\text { 1) Rapid } \\
\text { 2) High spatial resolution } \\
\text { 3) Better in-stent restenosis } \\
\text { visualization than MRA } \\
\text { 4) Faster than MRA }\end{array}$ & $\begin{array}{l}\text { 1) Scan of heavily calcified } \\
\text { vessels } \\
\text { 2) Use of iodinated contrast } \\
\text { 3) Exposure to radiations }\end{array}$ \\
\hline
\end{tabular}


was performed using 7.5 MHZ linear transducer connected to Toshiba (diagnostic ultrasound system Model TUS-X100). A 3.5 MHZ transducer was used in obese patients and those with severe subcutaneous edema. Inclusion criteria, all patients clinical symptoms of PAD (diabetic, hypertensive, hyperlipidemics). Exclusion criteria, Patients having findings like low/high PSV, biopsy pantheon, abscess, reduced flow in dorsalispedis artery, venous congestion, arterial congestion, stenosis or lymphadenopathy were excluded.

\section{Results}

During the one year study twelve males and twenty two females, patients between ag range 40 to 88 years with lower limbswelling, intermittent claudication, gangrene with diabetes mellitus were most indication for arterial Doppler ultrasonography clinically diagnosed peripheral arterial disease with diabetes, hypertension and hyperlipidemia (Table 2). Patients having findings like low/high PSV, biopsy pantheon, abscess, reduced flow in dorsalispedis artery, venous congestion, arterial congestion, stenosis or lymphadenopathy were excluded.

Grade I, II, III and IV stenosis were defined as PAD in this study, Table 3 shows number of patients with normal or grade 1 - 4 stenosis by Doppler. Figure 1(a) \& Figure 1(b) show normal Doppler ultrasound of right femoral artery.

\section{Discussion}

This study suggestive that color Doppler an excellent tool for evaluation of lower extremity arterial diseases. Color Doppler arterial mapping is sufficient for decision making in the treatment these patients and can reduce rate and risks involved in performing of diagnostic angiography, CT angiography, magnetic resonance angiography (MRA) and DSA (digital subtraction angiography) in many developing countries. Doppler Ultrasound is a non-invasive and safe technique. It is widely available and can be performed with virtually no risk of morbidity when compared with conventional angiography. Though angiography has benefit of being used as diagnostic and therapeutic purpose, there are well document risks with the use [16] [17]. Studies [18] have shown the sensitivity and

Table 2. General and clinical characteristics of participants.

\begin{tabular}{cc}
\hline General characteristics & Patients with peripheral arterial diseases $\mathbf{N}=\mathbf{3 6}$ \\
\hline Gender n (\%) & $12(33 \%)$ \\
Male & $22(67 \%)$ \\
Female & \\
Age: Years & $40-88$ \\
Mean (SD) & 23 \\
Diabetes mellitus & 7 \\
Diabetes mellitus + Hypertension & 6 \\
Diabetes Mellitus + Hypertension + & \\
Hyperlipidemics &
\end{tabular}


Table 3. Show the no. of patients with grade, $1-4$ of stenosis by Doppler.

\begin{tabular}{|c|c|c|c|}
\hline Grading & $\begin{array}{l}\text { Percentage of arterial } \\
\text { stenosis in lower limb }\end{array}$ & $\begin{array}{l}\text { Doppler ultrasound } \\
\text { finding }\end{array}$ & $\begin{array}{c}\text { Number of } \\
\text { patients } N=36\end{array}$ \\
\hline Normal & - & Normal triphasic flow & 9 \\
\hline Grade 1 & $1 \%$ to $19 \%$ stenosis & Normal triphasic flow & 12 \\
\hline Grade 2 & $20 \%$ to $49 \%$ stenosis & $\begin{array}{l}\text { Triphasic waveform with an } \\
\text { increase in peak systolic velocity } \\
\geq 30 \% \text { with respect to the } \\
\text { proximal recording site }\end{array}$ & 9 \\
\hline Grade 3 & $50 \%$ to $99 \%$ stenosis: & $\begin{array}{l}\text { Monophasic waveform with an } \\
\text { increase in peak systolic velocity } \\
\geq 100 \% \text { and marked spectral } \\
\text { broadening. Distal waveform is } \\
\text { abnormal }\end{array}$ & 4 \\
\hline Grade 4 & $100 \%$ stenosis: & & 2 \\
\hline
\end{tabular}

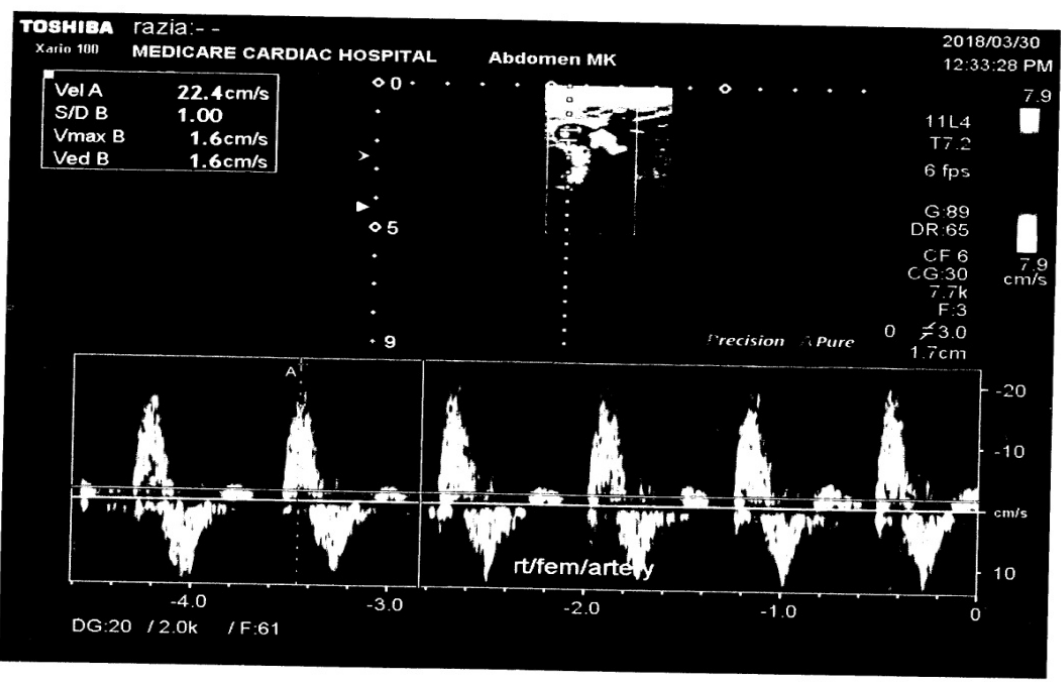

(a)

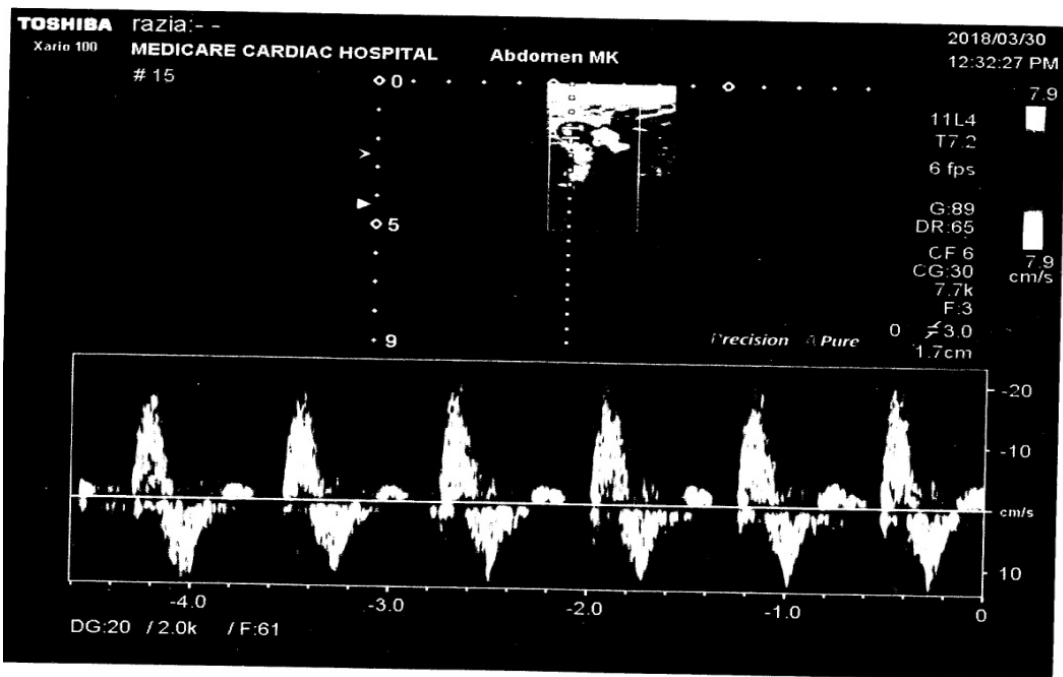

(b)

Figure 1. (a) \& (b): show normal Doppler ultrasound of right femoral artery. 
specificity of ultrasound for detection of PAD being non-invasive compared to standard angiography [19] [20]. Duplex ultrasound provides both vascular imaging and flow velocity information and has been shown to be an accurate method to diagnose the location and severity of lower extremity PAD with both sensitivity and specificity greater than $90 \%$ [18].

Other diagnostic modalities CT, MRI and angiography have shown rise in contrast induced nephropathy, additional contrast load, systemic sclerosis, and patients limitation (e.g. pacemakers) [21]. In addition they are more expensive than compare to Doppler ultrasonography [22].

Our study has demonstrated that DUS (duplex ultrasound) is accurate in determining the degree of stenosis present in lower extremity (PVD) peripheral vascular diseases.

\section{Conclusion}

Color doppler has proved excellent in the evaluation of lower extremities arterial diseases. Color doppler mapping is sufficient for decision making in the management of peripheral vascular diseases and reduces the risk and cost of diagnosis compared to CT angiography, magnetic resonance angiography (MRA) and DSA (digital subtraction angiography) specially in developing countries.

\section{References}

[1] Tang, G.L., Chin, J. and Kibbe, M.R. (2010) Advances in Diagnostic Imaging for Peripheral Arterial Disease. Expert Review of Cardiovascular Therapy, 8, 1447-1455. https://doi.org/10.1586/erc.10.134

[2] Bradbury, A.W. and Adam, D.J. (2007) Diagnosis of Peripheral Arterial Disease of the Lower Limb. BMJ, 334, 1229-1230. https://doi.org/10.1136/bmj.39244.344664.80

[3] Wong, T.H., Tay, K.H., Sebastian, M.G. and Tan, S.G. (2013) Duplex Ultrasonography Arteriography as First-Line Nvestigation for Peripheral Vascular Disease. Singapore Medical Journal, 54, 271-274. https://doi.org/10.11622/smedj.2013107

[4] Pollak, A.W., Norton, P. and Kramer, C.M. (2012) Multimodality Imaging of Lower Extremity Peripheral Arterial Disease: Current Role and Future Directions. Circulation: Cardiovascular Imaging, 5, 797-807. https://doi.org/10.1161/CIRCIMAGING.111.970814

[5] Roditi, G. and Kusumawidjaja, D. (2009) Magnetic Resonance Angiography and Computed Tomography Angiography for Peripheral Arterial Disease. Imaging, 21, 85-108. https://doi.org/10.1259/imaging/55671114

[6] Hagspiel, K.D., Flors, L., Hanley, M. and Norton, P.T. (2015) Computed Tomography Angiography and Magnetic Resonance Angiography Imaging of the Mesenteric Vasculature. Techniques in Vascular and Interventional Radiology, 18, 2-13. https://doi.org/10.1053/j.tvir.2014.12.002

[7] Hwage, J.Y. (2017) Doppler Ultrasonography of the Lower Extremity Arteries: Anatomy and Scanning Guidelines. Ultrasonography, 36, 111-119. https://doi.org/10.14366/usg.16054

[8] Leiner, T., Kessels, A.G., Nelemans, P.J., Vasbinder, G.B., de Haan, M.W., Kitslaar, P.E., Ho, K.Y., Tordoir, J.H. and van Engelshoven, J.M. (2005) Peripheral Arterial Disease: Comparison of Color Duplex US and Contrast-Enhanced MR Angiography 
for Diagnosis. Radiology, 235, 699-708. https://doi.org/10.1148/radiol.2352040089

[9] Helan, J.F., Barry, M.H. and Moir, J.D. (1992) Color Flow Doppler Ultrasonography: Comparison with Peripheral Arteriography for the Investigation of Peripheral Vascular Disease. Journal of Clinical Ultrasound, 20, 369-374.

[10] Eraso, L.H., Fukaya, E., Mohler 3rd, E.R., Xie, D., Sha, D. and Berger, J.S. (2014) Peripheral Rterial Disease, Prevalence and Cumulative Risk Factor Profile Analysis. European Journal of Preventive Cardiology, 21, 704-711. https://doi.org/10.1177/2047487312452968

[11] Criqui, M.H. and Aboyans, V. (2015) Epidemiology of Peripheral Artery Disease. Circulation Research, 116, 1509-1526. https://doi.org/10.1161/CIRCRESAHA.116.303849

[12] Olin, J.W. and Sealove, B.A. (2010) Peripheral Artery Disease: Current Insight into the Disease and Its Diagnosis and Management. Mayo Clinic Proceedings, 85, 678-692. https://doi.org/10.4065/mcp.2010.0133

[13] American Diabetes Association (2003) Peripheral Arterial Disease in People with Diabetes. Diabetes Care, 26, 3333-3341. https://doi.org/10.2337/diacare.26.12.3333

[14] Collins, R., Cranny, G., Burch, J., Aquair-Ibanez, R., Craig, D., Wright, K., Berry, E., et al. (2007) A Systematic Review of Duplex Ultrasound, Magnetic Resonance Angiography and Computed Tomography Angiography for the Diagnosis and Assessment of Symptomatic, Lower Limb Peripheral Arterial Disease. Health Technol. Assess, 11, 1-184.

[15] Jager, K.A., Phillips, D.J., Martin, R.L., Hanson, C., Roederer, G.O., Langlois, Y.E., et al. (1985) Noninvasive Mapping of Lower Limb Arterial Lesions. Ultrasound in Medicine \& Biology, 11, 515-521. https://doi.org/10.1016/0301-5629(85)90164-4

[16] Moneta, G.L., Yeager, R.A., Lee, R.W. and Porter, J.M. (1993) Noninvasive Localization of Arterial Occlusive Disease: A Comparison of Segmental Doppler Pressures and Arterial Duplex Mapping. Journal of Vascular Surgery, 17, 578-582. https://doi.org/10.1016/0741-5214(93)90158-I

[17] Franz, R.W., Jump, M.A., Spalding, M.C. and Jenkins, J.J. (2013) Accuracy of Duplex Ultrasonography in Estimation of Severity of Peripheral Vascular Disease. International Journal of Angiology, 22, 155-158.

https://doi.org/10.1055/s-0033-1336830

[18] De Vries, S.O., Hunink, M.G. and Polak, J.F. (1996) Summary Receiver Operating Characteristic Curves as a Technique for Meta-Analysis of the Diagnostic Performance of Duplex Ultrasonography in Peripheral Arterial Disease. Academic Radiology, 3, 361-369. https://doi.org/10.1016/S1076-6332(96)80257-1

[19] Hiatt, W.R. (2001) Medical Treatment of Peripheral Arterial Disease and Claudication. The New England Journal of Medicine, 344, 1608-1621. https://doi.org/10.1056/NEJM200105243442108

[20] Ismail, A., Saleh, M.K., Tabari, A.M. and Isyaku, K. (2015) Clinical and Doppler Ultrasound Evaluation of Peripheral Arterial Diseases in Kano, North-Western Nigeria. Nigerian Postgraduate Medical Journal, 22, 217-222. https://doi.org/10.4103/1117-1936.173971

[21] Ozkok, S. and Ozkok, A. (2017) Contrast-Induced Acute Kidney Injury: A Review of Practical Points. World Journal of Nephrology, 6, 86-99. https://doi.org/10.5527/wjn.v6.i3.86

[22] Collins, R., Cranny, G., Burch, J., Aguiar-Ibáñez, R., Craig, D., Wright, K., Berry, E., Gough, M., Kleijnen, J. and Westwood, M.A. (2007) Systematic Review of Duplex 
Ultrasound, Magnetic Resonance Angiography and Computed Tomography Angiography for the Diagnosis and Assessment of Symptomatic, Lower Limb Peripheral Arterial Disease. Health Technology Assessment, 11, 1-184.

https://doi.org/10.3310/hta11200 